\title{
El potencial de la Ley de Educación Superior a partir de su proceso de creación y adopción
}

\author{
Helga Cuéllar
}

\section{Resumen}

Este artículo expone un análisis sobre el surgimiento de la Ley de Educación Superior. Explica cómo, en cada etapa, se entrelazaron los intereses públicos y privados, lo cual al mismo tiempo generó enormes controversias, puesto que en todo proceso de creación y adopción de la política pública siempre existe una tensión inherente entre ambos intereses (públicos y privados) que finalmente se vuelve político. En este caso, la política educativa pública se efectuó mediante una metodología de consenso, lo cual implementó una cobertura a los gestores de la ley sobre otras formas de hacer políticas gubernamentales.

\section{Introducción}

Desde siempre se ha dicho que el fin último de cualquier política pública debe ser darle solución a un problema social o alcanzar una meta que beneficie a toda la población ${ }^{1}$. Pero el problema para hacer valer en la práctica tal afirmación ha estado simultáneamente ligado a las diferentes concepciones que varios actores sociales tienen respecto a lo que le afecta negativamente a la sociedad y le conviene ambicionar a largo plazo.

En términos generales, el proceso de creación y adopción de las políticas públicas involucra a

1. Ver Grover, Starling. The Politics and Economics of Public Policy: An Introductory Analysis with Cases, The Dorsey Press, Homewood, Illinois, 1979. Finifter, David; Baldwin, Roger y Thelin, John. The Uneasy Public Policy Triangle in Higher Education: Quality, Diversity and Budgetary Efficiency, American Council on Education, McMillan series on Higher Education, 1991. Preston, L.E. y Post, J.E. Private Management and Public Policy: The Principle of Public Responsability, Englewood Cliffs, N.J.: Prentice Hall, 1975. 
una serie de grupos sociales que, por un lado, podrán ser parte del sector público o privado; y por otro, tendrán intereses distintos. Unos más orientados hacia el bien de toda la sociedad y otros hacia el bienestar individual. Por lo tanto, en todo proceso de creación y adopción de la política pública siempre existe una tensión inherente entre los intereses públicos y privados el cual se vuelve una cuestión meramente política que debe ser resuelta.

La tensión entre intereses públicos y privados puede variar según el tipo de la política propuesta (educativa, económica, de transporte, etc.), el grado de aceptación social que ésta tenga y el contexto social en que ésta sea discutida. Dicha tensión siempre existe, pero hasta qué punto se convierta en un asunto crítico dependerá de las circunstancias en que ésta se desarrolle y cómo sea manejada. Por consiguiente, el potencial de éxito que una política pública tiene para resolver un problema dependerá un tanto en cómo el conflicto de intereses entre diversos actores sea resuelto. Hay varias maneras de reducir o eliminar este tipo de controversias durante el proceso de creación y adopción de la política pública, pero no todas garantizan el éxito en su implementación. ¿Cuál será el mejor método?... Dejémosle a los hacedores de la política pública escoger o crear la mejor opción posible.

En El Salvador, el proceso de creación y adopción de la Ley de Educación Superior aprobada en 1995 constituye un claro ejemplo de cómo la tensión entre intereses públicos y privados se da en la práctica. En este caso, el principal conflicto de intereses surgió, más que todo, entre los hacedores de la política educativa pública, como el MINED y la Asamblea Legislativa, y el sector de las universidades. La estrategia usada para conducir el proceso estuvo basada en los principios de participación y negociación; en otras palabras, se basó en una metodología de consenso. Así se logró resolver la tensión entre intereses públicos y privados. Pero, ¿cuál es el potencial de éxito que tiene una ley de educación superior basada en el consenso?... ¿Puede una metodología de consenso garantizar que esta ley constituya un mecanismo auténtico que ayude a resolver los problemas actuales de la educación superior? ¿Qué lecciones podemos aprender a partir del estudio de este caso concreto? No podemos responder a ninguna de estas inquietudes sin antes hacer un breve análisis de lo que fue el proceso de creación y adopción de la ley de educación superior.

\section{Creación y adopción de la Ley de Educación Superior}

Comenzaremos aclarando que si bien es cierto el caso salvadoreño que analizaremos a continuación puede ayudar a comprender mejor la naturaleza, el impacto y el potencial de éxito que puede tener una política para el sector de educación superior, éste no es ni el único ni es universal. Pero eso sí, su análisis nos demostrará que en verdad todo proceso de creación y adopción de una política pública está cargado de una serie de conflictos, agendas privadas y otras sutilezas que no son usualmente mencionadas a pesar de su relevancia.

A lo largo del análisis sobre la creación y adopción de esta ley podrá reconocerse cada una de las etapas que encierra este proceso y la función que desempeñaron los actores que más influyeron en éste. El proceso comienza con la identificación del problema, luego se formula la política para darle solución, se legitimiza, se implementa y finalmente se evalúa. A nosotros de momento sólo nos interesan las primeras cuatro etapas. Habremos de recordar, entonces, que desde su creación hasta su adopción, el devenir de la ley de educación superior estuvo en función de cómo los intereses públicos y privados se fueron combinando en cada momento. Veamos a continuación cómo se presentó esto.

\subsection{El marco legal inadecuado de la educación universitaria}

Originalmente, la educación superior en El Salvador era ofrecida a través de una sola institución: la Universidad Nacional de El Salvador (UES). Desde su creación en 1841 , la UES había estado tradicionalmente bajo directa vigilancia del gobiemo, de allí que el monopolio de la educación superior era absolutamente administrado y controlado por el Estado. Fue hasta en 1950 que reformas a la constitución nacional otorgaron a la UES independencia para llevar a cabo su gestión académica, administrativa y económica. Aun cuando la UES nunca dejó de ser una universidad del Estado, las nuevas condiciones le permitieron 
determinar cuáles serían sus propios instrumentos normativos ${ }^{2}$. Así, un año más tarde, se creó la Ley Orgánica de la Universidad de El Salvador; y, por primera vez, se estableció un marco legal para la educación superior respetando los derechos de su autonomía.

De 1951 a mediados de los sesenta, los únicos instrumentos para controlar el monopolio de la educación superior eran la Constitución Nacional y la Ley Orgánica de la Universidad de El Salvador. Pero debido a presiones de tipo social, económico y político, a este marco legal se añade la Ley de Universidades Privadas creada en 1965.

Las presiones de tipo social tenían relación con la incapacidad de la UES para absorber la creciente demanda educativa de aquella época. Evidencia disponible nos muestra que en 1962 sólo el 30 por ciento de los egresados de secundaria, que eran aptos para ingresar a la universidad, pudieron continuar sus estudios universitarios ${ }^{3}$. Este hecho hace cuestionar hasta qué punto era pertinente consignar la oferta de servicios universitarios al sector público cuando había demandas educativas insatisfechas. A raíz de este debate se concluyó que la educación universitaria no debía ser una responsabilidad única del Estado por lo que había que promover el surgimiento de instituciones privadas a fin de ampliar la cobertura de los servicios educativos. Se pensó que a través de la creación de la Ley de Universidades Privadas se podría dar solución al problema de acceso a la educación superior.

Según Mallat, ${ }^{`}$ las presiones de tipo económico estaban relacionadas con la necesidad de mejorar la calidad del recurso humano en el marco de las estrategias de crecimiento y desarrollo económico basadas en el modelo de sustitución de importaciones. En este caso, el posibilitar mayores oportunidades para la formación científica y técnica mediante la creación del sector universitario privado contribuiría en la creación de un capital humano más productivo y eficiente capaz de forjar el crecimiento económico del país. Este planteamiento, además, ayudaba a justificar la necesidad de promover el aparecimiento de instituciones universitarias nuevas y de naturaleza jurídica privada.

En el ámbito político, fueron los crecientes conflictos entre el gobierno y la Universidad de El Salvador los que influyeron en los hacedores de la política pública en su deseo de impulsar al sector privado a que participara en el ofrecimiento de los servicios educativos universitarios. En varias ocasiones se sugirió que dado que la UES representaba una importante fuerza política de oposición, el facilitar la creación de universidades privadas no fue más que una sutil estrategia para reducir el poder político de dicha institución ${ }^{5}$.

Mientras el marco legal de la educación universitaria pública se constituyó en un recurso legítimo para asegurar la autonomía de la UES, la Ley de Universidades Privadas se convirtió en un esfuerzo claro para promover la expansión educativa a nivel superior. Con el paso de los años, el establecimiento de dos marcos legales, uno que regulara sólo a las instituciones privadas y otro sólo a la UES, se volvió inadecuado por diferentes razones. En primer lugar, en ningún momento se pensó en diseñar un sistema normativo coherente mediante el cual todas las instituciones universitarias, ya sean privadas o públicas, fueran tratadas

2. Samayoa y González. "Educación Superior Universitaria en El Salvador", en Diagnóstico del Sistema de Desarrollo de Recursos Humanos en El Salvador, Estudio realizado por Harvard Institute for International Developmet, FEPADE y UCA, San Salvador, El Salvador, No 7, 1994, p. 2.

3. Op. cit., p. 4

4. Mallat, Gustavo. Realidad de la educación universitaria en El Salvador, FUSADES, San Salvador, El Salvador, 1991.

5. Proyecto UCA/PEDE-OEA. La investigación y la docencia en la educación universitaria de El Salvador, San Salvador, Junio, 1990. 
igualmente ante la ley. En segundo lugar, no había una clara definición sobre lo que debía ser entendido como educación superior y cuáles debían ser los principios y fines de tal sector. Había, entonces, un vacío legal pues no existía nada que regulara simultáneamente a todas las instituciones de educación superior tanto universitaria como técnica.

Finalmente, lo inadecuado del marco jurídico se hizo manifiesto una vez que la Ley de Universidades Privadas se implementó. Esta ley se caracterizó por ser poco rigurosa y permisiva en relación con los requisitos mínimos para constituir una institución universitaria. De allí que en la praxis, la Ley de Universidades Privadas fomentó un incremento en el número de instituciones acompañado de una disminución en la calidad de la educación ofrecida.

\subsection{El boom de universidades}

Además de la guerra civil, la inestabilidad política y la crisis económica, el acelerado crecimiento de las universidades privadas fue uno de los hechos que caracterizaron la década de los ochenta. El boom de universidades no fue un resultado exclusivo de las ineficiencias del marco jurídico existente. Otros factores de tipo político y social también contribuyeron a que esto ocurriera.

El cierre de la Universidad de El Salvador y la intervención militar a su campus desviaron la creciente demanda de educación universitaria hacia las primeras instituciones privadas existentes. Según Samayoa, "se especula que el gobiemo habría facilitado la apertura de universidades privadas con el propósito de disgregar a la población estudiantil, que en momentos similares en el pasado se había constituido en un fuerte movimiento social de oposición al gobierno"6. Independientemente de los motivos para el cierre de la UES, como consecuencia de esta acción muchos estudiantes se vieron forzados a ingresar a una de las cinco universidades que ya habían sido creadas: Universidad Centroamericana "José Simeón Cañas", UCA, (1965); Universidad Albert Einstein, (1977); Universidad Dr. José Matías Delgado (1977), Universidad Politécnica de El Salvador, (1979); y la Universidad Salvadoreña Alberto Masferrer, USAM (1980).

Pese a la existencia de otras opciones educativas, se estima que un número considerable de estudiantes habría quedado al margen, lo cual dio lugar a que el "mercado de la educación universitaria" se volviera atractivo en términos rentables para algunos inversionistas de la empresa privada.

Según datos del Ministerio de Educación (MINED), sólo en los ochenta se crearon treinta y tres universidades privadas: siete en 1981, 12 en 1982 , seis entre 1983 y 1986, y ocho entre 1987 y finales de 1989. Para finales de los noventa, éstas alcanzaron un número de 38. Además, habría que tomar en cuenta la creación, en 1988 , de la segunda universidad estatal, la Universidad Militar?

En suma, a principios de los noventa, El Salvador contaba con cuarenta universidades, mientras que en otros países de Centroamérica la media de instituciones apenas alcanzaba un número de ocho. Este dato por sí mismo es bastante elocuente en relación con la calidad del servicio educativo que podía estarse ofreciendo. Datos disponibles ayudan a describir la situación del sector de universidades privadas que todavía predomina.

Es necesario señalar que para 1991, estas universidades absorbían el 68 por ciento del total de la matrícula en todo el país. La mayoría de las instituciones operaba en pequeñas residencias, muchas veces alquiladas, que habían sido readecuadas para funcionar como salones de clases $y$

6. Samayoa, Joaquín. "Problemas y perspectivas de las universidades privadas en El Salvador, ECA, mayo-junio, 1994, p. 471.

7. MINED. Educación Superior en Cifras: 1991-1992, Nueva San Salvador, El Salvador, 1992. 
oficinas. Unicamente 10 instituciones universitarias poseían instalaciones adecuadas para facilitar el proceso de enseñanza y aprendizaje $^{8}$. En general, la mayoría de las universidades privadas carecía de apropiada infraestructura, laboratorios, equipos y hasta de un número considerable de profesores a tiempo completo para dedicarse plenamente a la docencia e investigación. De hecho, en 1991, de 2,079 profesores que trabajaban en el sector privado, el 80 por ciento había sido contratado por hora clase impartida ${ }^{9}$.

No había ningún mecanismo para controlar la calidad de la educación universitaria. La Ley de Universidades Privadas fomentaba la apertura de instituciones y era muy vaga al definir los requisitos mínimos para asegurar la calidad de la educación. No era extraño que muchas de las universidades estaban viciadas por actos de corrupción, como la "venta de títulos", y la apertura de carreras sin haber sido aprobadas por el MINED, entre otros. Además, no existía ninguna instancia oficial comprometida y con capacidad para velar por la sanidad del sistema de la educación superior en su totalidad; y más aún, que velara por la eficiencia y calidad de la educación universitaria.

A fin de corregir todas estas irregularidades, a mediados de los ochenta, el ministro de educación, Prof. Buendía Flores, realizo los primeros intentos para establecer un nuevo marco jurídico que normara la educación superior. Para ello, se llevó a cabo un proceso de consulta informal con diferentes universidades que desembocó en el aparecimiento de varias propuestas de ley alternativas. Entre las más importantes se encuentran las presentadas por el Ministerio de Educación, la
Universidad de El Salvador, la Universidad Centroamericana "José Simeón Cañas" y el Consejo Superior de Universidades Privadas (COSUPES) ${ }^{10}$.

Cuatro corrientes principales definían el propósito original de la ley que debía crearse. Para el MINED, ésta habría de constituirse en un mero mecanismo para regular y controlar al sector de educación superior. Desde su perspectiva, el nuevo marco jurídico serviría para detener el boom de universidades y reducir el derecho de autonomía de la Universidad de El Salvador, a fin de mermar el excesivo activismo político que se generaba allí. La propuesta de la Universidad de El Salvador, por el contrario, no era más que un nuevo artificio para reafirmar y asegurar su hegemonía sobre el resto de las universidades. La de COSUPES, por su parte, pretendía velar más que todo por la autonomía económica y administrativa de las universidades privadas. Mientras que la propuesta de la UCA estaba orientada a definir cuáles debían ser los criterios para garantizar la calidad educativa, y hasta qué punto el derecho de autonomía debía ser restringido por el Estado.

8. Samayoa, J. Op. cit. p. 482

9. MINED. Op. cit.

10. Esta organización fue creada en los ochenta. Esta pretendía proteger los intereses de algunas universidades privadas. Inicialmente estaba formado por quince instituciones como la Universidad Autónoma de Santa Ana, Universidad Santaneca de Ciencia y Tecnología, Universidad Capitán General Gerardo Barrios, Universidad Modular Abierta, Universidad Leonardo Da Vinci, Universidad Tomás Alva Edison, Universidad Francisco 
Pero ninguna de estas propuestas tuvo mayor trascendencia debido a la diferencia de intereses entre las universidades y el Ministerio de Educación. Por un lado, cada iniciativa pretendía dar respuesta al mismo problema desde su propia óptica. Y, por otro lado, éstas habían surgido aisladamente y sin dejar un espacio para ser discutidas constructivamente a través de los medios de comunicación, y/o a través de las instancias responsables de la generación de políticas educativas a escala nacional. En suma, el problema consistía en que no había ningún tipo de acuerdo sobre el contenido y el propósito del nuevo marco jurídico para la educación superior, puesto que los intereses privados predominaban frente a los intereses públicos. Imperaba, entonces, la necesidad de consolidar los diferentes puntos de vista bajo una sola propuesta de ley.

\subsection{Necesidad de una ley basada en el consenso}

En 1991, bajo la dirección de la ministra Cecilia Gallardo de Cano, el MINED genera las condiciones para establecer un consenso mínimo en tomo a lo que debía ser la propuesta de ley que regularía a todo el sector de educación superior. Para ello, el MINED pidió a algunas instituciones su colaboración en el diseño de una propuesta de ley para la educación superior que debería ser posteriomente presentada a la Asamblea Legislativa para su aprobación. Consecuentemente se creó un comité de aproximadamente seis personas integrado por representantes de la Universidad Centroamericana "José Simeón Cañas", la Universidad de El Salvador y el MINED. Estas tres instituciones estaban de acuerdo en que era indispensable tener un marco jurídico único que regulara la educación superior, promoviera la calidad educativa y garantizara una mayor contribución del sector en el desarrollo del país. Sin embargo, había ciertas discrepancias en varios aspectos, entre ellos, los más controvertidos se referían a las funciones de una universidad, los requerimientos mínimos para asegurar un servicio de calidad, los derechos de autonomía, y quién debía ser el verdadero responsable de controlar y organizar al sector de educación superior (ver Cuadro 1).

\section{Cuadro 1 \\ Principales puntos de contención \\ entre las propuestas del MINED, la UES y la UCA}

\begin{tabular}{|c|c|c|c|}
\hline Puntos de conlención & MINED (1990)" & UES (junio 1990) & UCA (julio 1992) \\
\hline Funciones de la universidad & $\begin{array}{l}\text { - Tener estatutos y otras } \\
\text { regulaciones } \\
\text { - Programas de estudio apro- } \\
\text { bados } \\
\text { - Material educativo disponible } \\
\text { - Profesionales calificados } \\
\text { - Infraestructura adecuada }\end{array}$ & $\begin{array}{l}\text { - Analizar la realidad } \\
\text { - Promover el cambio } \\
\text { - Investigar } \\
\text {-Formar a los maestros de } \\
\text { todo el sistema educativo } \\
\text { - Un mínimo de tres facultades } \\
\text { (ciencias y humanidades) } \\
\text { - Programas de estudio } \\
\text { semejantes a los de la UES } \\
\text { - Tener estatulos } \\
\text { - Infraestructura adecuada }\end{array}$ & $\begin{array}{l}\text { - Un mínimo de ocho carreras } \\
\text { - Una investigación anual } \\
\text {-25\% de profesores a tiempo } \\
\text { completo } \\
\text {-Al menos } 2 \text { profesores } \\
\text { con posgrado por cada espe- } \\
\text { cialidad } \\
\text { - Programas aprobados } \\
\text { - Infraestructura adecuada }\end{array}$ \\
\hline
\end{tabular}

Gavidia, Universidad Tecnologica, Universidad Evangélica de El Salvador, Universidad Nueva San Salvador, Universidad Las Américas de El Salvador, Universidad Católica de Occidente, Universidad Metropolitana de El Salvador, Universidad Pedagógica de El Salvador, y la Universidad Técnica Latinoamericana. 


\begin{tabular}{|c|c|c|c|}
\hline Derechos de autonomía & $\begin{array}{l}\text { - En lo académico, financiero } \\
\text { y administrativo } \\
\text { - La universidad estatal debe } \\
\text { ser controlada por el fisco } \\
\text { - No derecho al activismo } \\
\text { político } \\
\text { - El marco jurídico de la UES } \\
\text { debe ser compatible con el de } \\
\text { toda la educación superior } \\
\text { - No fines de lucro }\end{array}$ & $\begin{array}{l}\text {-UES continuara siendo regu- } \\
\text { lada por la Constitución Na- } \\
\text { cional y sus estatutos internos } \\
\text { - No control fiscal } \\
\text { - } 5 \% \text { de presupuesto nacional } \\
\text { debe ser destinado a la UES } \\
\text { - No fines de lucro }\end{array}$ & $\begin{array}{l}\text {-UES debe conservar su } \\
\text { derecho de autonomía } \\
\text { - El control fiscal sólo debe ser } \\
\text { exigido para constatar la } \\
\text { legalidad del gasto } \\
\text { - No intervención de los } \\
\text { "patrocinadores legales" } \\
\text { - No fines de lucro }\end{array}$ \\
\hline Organismos de control & — MINED a través de DES & $\begin{array}{l}\text { - CES. Integrado por represen- } \\
\text { tantes del MINED, de la } \\
\text { UES, universidades privadas } \\
\text { y los institutos técnicos }\end{array}$ & $\begin{array}{l}\text {-CES: integrado por } 7 \text { repre- } \\
\text { sentantes: MINED }-1 \text {, } \\
\text { MIPLAN** - } 2 \text {, } \\
\text { UES }-1 \text {, UCA }-1 \text {, Otras } \\
\text { universidades privadas }-1 \text {, } \\
\text { e institutos técnicos }-1\end{array}$ \\
\hline
\end{tabular}

- Basado en las propuestas de julio y diciembre de 1990.

* Actualmente este ministerio no existe.

El primer punto de contención estaba relacionado con lo que debía ser entendido como las grandes funciones de la universidad. Aun cuando la UES, la UCA y el MINED coincidían en que las grandes funciones de la universidad debian ser la docencia, investigación y proyección social, habia dificultad en explicar el alcance de tales funciones en el interior y exterior de la universidad. Fue la UCA quien logró definir con mayor detalle estas funciones. En su propuesta de 1992, se definía que a través de la proyección social las universidades debían promover el cambio social; a través de la investigación, la constante búsqueda racional y científica de las causas y efectos de todos los problemas de nuestra sociedad; y a través de la combinación de estas dos primeras funciones, la docencia debía convertirse en una experiencia enriquecedora ${ }^{11}$.

En cuanto a los requerimientos de calidad, estas instituciones planteaban que desde una perspectiva legal y práctica, la calidad educativa debía ser medida a partir del cumplimiento de un mínimo de requisitos institucionales. Para el MINED, estos requisitos tenían relación con la existencia de estatutos y programas de estudio aprobados, profesores competentes, cantidad de material educativo disponible y la existencia de una infraestructura adecuada.

En adición a los requisitos anteriores, la Universidad de El Salvador señalaba la importancia de tener al menos tres facultades (ciencias y humanidades), así como implementar programas de estudio que fueran al menos iguales a los de la universidad nacional. Sin duda, a la Universidad de El Salvador le interesaba, además, mantener su supremacía sobre el resto de las universidades. Por su parte, la UCA añadía algunos requisitos de calidad no sólo más estrictos sino también menos cualitativos: un mínimo de 8 carreras, la realización de al menos 1 proyecto de investigación al año, tener un 25 por ciento de los profesores contratados a tiempo completo, y al menos 2 profesores por cada especialidad con grado de maestría o doctorado.

En relación con el tema de los derechos de autonomía, las tres posturas parecían sólo convergir en todo aquello relacionado con la autonomía financiera de las universidades privadas. Había un acuerdo absoluto en evitar que el derecho de autonomía fuera usado por algunas universidades priva-

11. Universidad Centroamericana “José Simeón Cañas”. Anteproyecto de Ley de Educación Superior, julio, 1992. 




educación superior, éste insistía en que la UES no debía gozar de autonomía absoluta. Por un lado, en su anteproyecto de ley, el MINED claramente afirmaba que: "la autonomía se refiere a lo académico, administrativo y financiero. Este último, sin perjuicio del control que prescriben las leyes de la república, cuando se trata de instituciones estatales"12. Y, por otro lado, el MINED señalaba en otro artículo de la misma propuesta que la Universidad de El Salvador debería estar sujeta a la fiscalización de la Corte de Cuentas de la República ${ }^{13}$. Esta iniciativa había surgido con el objetivo de eliminar la das a fin de justificar sus estrategias de rentabilidad económica en menoscabo de la excelencia educativa. Para el caso, se promulgaban en contra de la intervención de los llamados "patrocinadores legales", los cuales funcionaban como organizaciones aliadas a las universidades privadas a fin de proveerles servicios de alquiler de equipo e infraestructura y provisión de materiales educativos. Usualmente, estos organismos estaban formados por miembros de la junta directiva de la misma universidad; de allí que no había una diferenciación real entre la institución y su patrocinador. En la práctica, los "patrocinadores legales" no eran más que un artificio legal para transferir ganancias de la universidad a ciertos individuos, de esta manera se limitaba la posibilidad de aumentar los montos de inversión promejoramiento de la calidad educativa.

Pero el grueso de las discusiones entre la Universidad de El Salvador, la Universidad Centroamericana "José Simeón Cañas" y el MINED no se concentró en ninguno de los puntos anteriores. El tema de la autonomía y la determinación de los organismos de control del sector provocaron los enfrentamientos ideológicos más fuertes. En los extremos se encontraban la Universidad de El Salvador y el MINED, mientras que en términos globales la UCA parecía presentar la propuesta de ley más conciliatoria.

Pese a que el MINED reconocía el derecho de autodeterminación de todas las instituciones de mala administración de los fondos y, en muchos casos, hasta la comupción en la Universidad de El Salvador. Es interesante mencionar, además, que en uno de los anteproyectos de ley presentados por el MINED, incluso, se tomaba en cuenta un artículo en el cual se establecía que "ninguna universidad estatal, ni sus organismos como tales, podrán intervenir en actividades de política partidista, ni distraer en tales actividades parte de los bienes integrantes de su patrimonio"14. Esta prohibición al activismo político desde la Universidad de El Salvador, en el fondo, no pretendía ser más que un instrumento legal para evitar la notable influencia antigubernamental de la Universidad de El Salvador en la arena política de aquellos años.

En contraposición a la propuesta del MINED, la Universidad de El Salvador demandaba que se le garantizara su derecho supremo a la autonomía. No sólo rechazó aceptar la posible intervención de la Corte de Cuentas en sus finanzas, sino también descartó cualquier intento de amainar los privilegios legales que ya le habían sido conferidos a través de la Constitución Nacional de la República. En su lugar, la Universidad de El Salvador proponía que se le otorgara anualmente un 5 por ciento del presupuesto general de la nación, y que mediante la ley de educación superior se reafirmara su soberanía.

En medio de estas dos posiciones encontradas se hallaba el anteproyecto de ley de la UCA. Esta

12. MINED. Anteproyecto de Ley de Educación Superior, diciembre, 1990, Art. 65.

13. Op. cit., Art. 88.

14. MINED. Anteproyecto de Ley de Eduación Superior, julio, 1990, Art. 88. 
se propugnaba en favor de definir un marco jurídico que regulara a todas las instituciones por igual y sin ninguna excepción. Aun cuando reconocía el derecho de autonomía de la UES, la UCA estaba en favor de su fiscalización pero sin intervencionismos.

En cuanto al establecimiento de organismos de control y coordinación del sector, el MINED estaba en contra de abandonar su tarea reguladora que por naturaleza parecía competerle. El MINED pedía que fuera la Dirección de Educación Superior (DES), una de sus propias instancias, la responsable de vigilar por la sanidad del sector.

Según la UES y la UCA, la mejor opción era conferir esta tarea a una entidad autónoma y representativa de todo el sector a la cual ambas instituciones coincidieron en llamarle Consejo de Educación Superior (CES). La diferencia entre la UES y la UCA estaba en la manera de definir la composición y funciones de este consejo (CES).

Dadas las discrepancias entre el MINED, la
UES y la UCA, preparar una propuesta de ley integral o más bien basada en el consenso era un gran reto. Un grado mínimo de acuerdo habría de establecerse no sólo en relación con los principales puntos de contención mencionados anteriormente, sino también en tomo a otras diferencias menos controvertidas.

Considerando las características de la propuesta de la UCA - quizá con un enfoque más conciliador o bien menos polarizador- no fue raro el que esta institución se convirtiera en un importante mediador a fin de aminorar las tensiones entre el MINED y la UES. De hecho, como prueba de la capacidad de mediación que tuvo la UCA, tenemos que en 1993, el MINED presentó a la Asamblea Legislativa una propuesta de ley que tenía la misma estructura y el mismo número de artículos (146) que aquella elaborada por la UCA un año atrás. Aun en cuanto al contenido, muchas de las sugerencias planteadas por la UCA fueron las que prevalecieron (ver Cuadro 2).

\section{Cuadro 2}

Propuesta del MINED (julio, 1993)

Principales acuerdos establecidos entre UES, UCA y MINED

\begin{tabular}{|c|c|}
\hline Puntos de contención & Principales acuerdos \\
\hline $\begin{array}{l}\text { Funciones de la } \\
\text { universidad }\end{array}$ & $\begin{array}{l}\text { - Docencia, investigación y proyección social. Tal y como fueron } \\
\text { definidas por la UCA. }\end{array}$ \\
\hline $\begin{array}{l}\text { Requisitos mínimos } \\
\text { de calidad }\end{array}$ & $\begin{array}{l}\text { - Un mínimo de cinco carreras de estudio. } \\
\text { - Al menos un proyecto de investigación anual. } \\
\text { - } 25 \% \text { de profesionales contratados a tiempo completo. } \\
\text { - Al menos } 2 \text { profesores con posgrado por cada especialidad. } \\
\text { - Programa de estudios aprobado por el MINED. } \\
\text { - Infraestructura adecuada. } \\
\text { - Estatutos aprobados. }\end{array}$ \\
\hline $\begin{array}{l}\text { Derechos de } \\
\text { autonomía }\end{array}$ & $\begin{array}{l}\text { - Se reconocen los derechos de autonomía de la UES y la legitimidad de } \\
\text { su reglamento interno. } \\
\text { - La UES no podrá ser eximida del control fiscal, pero éste deberá ser } \\
\text { hecho únicamente para confirmar la legalidad de sus gastos. } \\
\text { - La UES deberá estar bajo la supervisión del CES. } \\
\text { - No fines de lucro. } \\
\text { - No intervención de los "patrocinadores legales" en las operaciones de } \\
\text { las universidades privadas. }\end{array}$ \\
\hline Organismos de control & $\begin{array}{l}\text { - CES. Integrado por } 7 \text { representantes: MINED } \\
-1 \text {, MIPLAN }-1 \text {, UES }-1 \text {, UCA }-1 \text {, el resto de universidades privadas }-2 \text {, } \\
\text { institutos técnicos }-1 \text {. }\end{array}$ \\
\hline
\end{tabular}


En suma, la propuesta de ley, que finalmente se llev6 al pleno de la Asamblea Legislativa en julio de 1993, fue el resultado de un necesario pero limitado consenso entre el MINED y las dos universidades de mayor antigüedad en el país. Estaba por verse cuál sería la reacción del resto de las instituciones de educación superior ante el nuevo proyecto de ley y, sobre todo, cuál sería el grado de aceptación que ésta tendría en muchas de las universidades privadas. Era de esperarse una nueva controversia.

\subsection{El controvertido proceso de legitimización}

En nuestro país, el proceso de legitimización de una ley comienza una vez hecha la propuesta formal a la Asamblea Legislativa. Según nuestra constitución, el derecho exclusivo de crear cualquier ley le pertenece a la Asamblea Legislativa, la Corte Suprema de Jus-

la propuesta de ley fue el resultado de un necesario pero limitado consenso entre el MINED y las dos universidades de mayor antigüedad en el país (UES Y UCA). anteproyecto de ley fue entregado a una de las comisiones de la asamblea para su estudio. Lo más lógico era que ésta fuera entregada a la Comisión de Cultura y Educación, no obstante, ésta fue entregada a la Comisión de Legislación y Constitución; y por varios meses el estudio de ley fue pospuesto. Según declaraciones del presidente de la Comisión de Educación y Cultura, Roberto Serrano, esta acción no fue producto de ningún error, sino más bien fue un claro boicot al proceso de legitimización de la ley provocado por algunas personas influyentes quienes tenían propiedad sobre algunas de las universidades privadas y temían verse afectados por las nuevas regulaciones ${ }^{17}$. Después de largos debates, la propuesta de julio de 1993 presentada por el MINED fue finalmente pasada a la Comisión de Educación y Cultura; y, por supuesto, junto a ella toda la controversia.

A mediados de 1994, la oposición alrededor de la creación de una ley de educación superior era más que evidente. Algunas universidades privadas criticaron fuertemente el contenido de la propuesta del MINED, e inclusive presentaron al pleno de la Asamblea Legislativa sus propias iniciativas de ley. Algunas de las observaciones más importantes a la propuesta del MINED fueron hechas por dos coaliciones: el Consejo Superior de Universidades Privadas (COSUPES), integrado por alrededor de 20 universidades privadas ${ }^{18}$; y la Asociación de Universidades Privadas de El Salvador (AUPRIDES), la cual había sido establecida desde principios de los noventa y estaba formada por cinco ex miembros de COSUPES ${ }^{19}$.

\section{Artículo 133.}

16. Comisiones en el interior de la Asamblea Legislativa: (1) cultura y educación, (2) defensa, (3) economía y agricultura, (4) hacienda y especial del presupuesto, (5) legislación y puntos constitucionales, (6) trabajo y previsión social, (7) relaciones exteriores e integración centroamericana, (8) política, (9) protección del medio ambiente y salud pública, (10) interior y seguridad pública, (11) obras públicas, (12) justicia y derechos humanos, (13) gracias y excusas, $y,(14)$ la familia, la mujer y el niño.

17. Entrevista, enero 10, 1995.

18. Entre las universidades que forman el COSUPES se encuentran la Universidad Pedagógica de El Salvador, Universidad Metropolitana, Universidad Técnica Latinoamericana, Universidad Capitán General Gerardo Barios, Universidad Modular Abierta, Universidad Leonardo Da Vinci, Universidad Tomás Alva Edison, Universidad Nueva San Salvador, Universidad Las Américas de El Salvador y la Universidad Salvadoreña.

19. Universidad Albert Einstein, Universidad Francisco Gavidia, Universidad Evangélica, Universidad Tecnológica y la Universidad Católica de Occidente. 
Estas dos coaliciones tenían en común querer proteger los intereses de las universidades privadas. Para el caso, ambas defendían su derecho a la autonomía económica y la no regulación de los "patrocinadores legales". No obstante, había una distinción importante entre ellas y su postura hacia la propuesta del MINED (ver Cuadro 3).

COSUPES estaba formado por las universidades más pequeñas que, por ende, carecían de la mayoría de los requerimientos de calidad definidos en el anteproyecto de ley que estaba siendo discutido en la asamblea. COSUPES reclamaba que la ley propuesta era excesivamente reguladora ${ }^{20}$ y atentaba en contra de los principios de la libre empresa. La propuesta del MINED, según afirmaron, era irrespetuosa de su derecho a la autonomía económica. De allí que COSUPES estuviera totalmente en contra del establecimiento de una mínima cuota de profesores contratados a tiempo completo dado que, a su juicio, en lugar de mejorar la calidad, esto sólo contribuiría a incrementar los costos de operación. En cuánto al establecimiento de organismos de control, COSUPES apoyaba la creación del CES siempre y cuando se considerara la incorporación de las asociaciones empresariales y las organizaciones de profesionales.

Cuadro 3

AUPRIDES y COSUPES: principales puntos de contención en relación con la propuesta del MINED

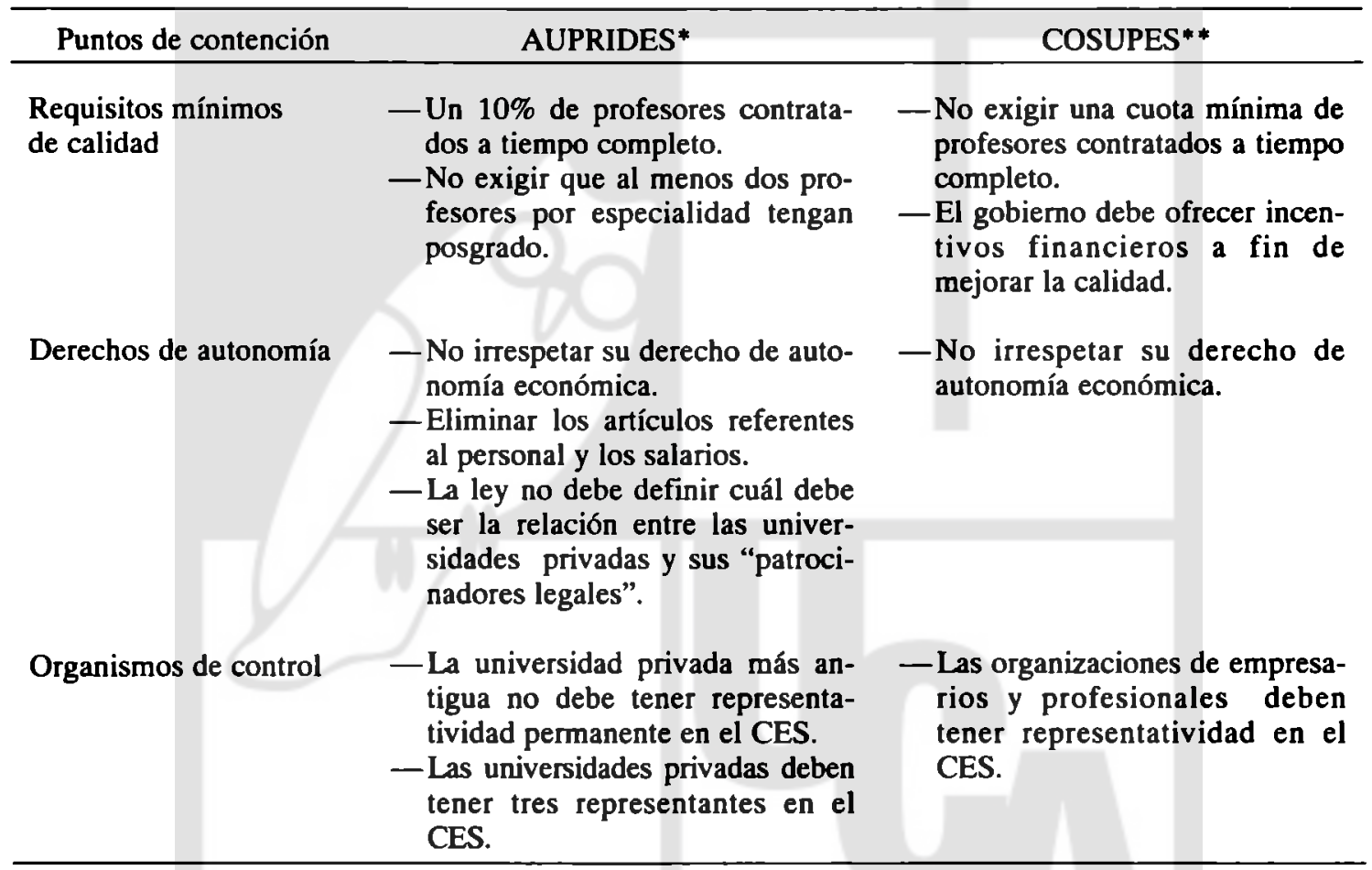

* Basado en la propuesta de AUPRIDES de agosto 1993; y en opiniones expresadas a través de La Prensa Gráfica y El Diario de Hoy.

** Basado en los comentarios expresados a través de La Prensa Gráfica y El Diario de Hoy.

20. En la ley propuesta se definían aspectos, tales como la duración de una clase (en $50 \mathrm{~min}$.), el número de unidades valorativas que se requerían para graduarse, el número de años que debería durar una carrera de estudios, los requisitos de graduación, entre otros. 
A diferencia de COSUPES, AUPRIDES estaba formado por universidades de tamaño mediano que en los últimos años habían experimentado un notable desarrollo institucional. En general, aún cuando señalaba que la ley propuesta era reguladora, esta coalición apoyaba la pronta creación de un nuevo marco jurídico para la educación superior. En otras palabras, en comparación a COSUPES, AUPRIDES parecía estar menos en contra de la propuesta del MINED. Su principal preocupación quizá no era el establecimiento de la ley en sí misma, sino más bien el que ésta no fuera realista y tuviera un impacto negativo en los costos de la educación superior. De hecho, esta coalición alegaba que si no existía ningún tipo de apoyo a las instituciones universitarias privadas para mejorar la calidad de sus servicios, no era justo implementar una ley que desalentara los esfuerzos económicos de muchas instituciones privadas. Los miembros de AUPRIDES no demandaban la eliminación de algunos requerimientos sino más bien que se revisara su viabilidad en la práctica. Ellos pedían, por ejemplo, que en la ley se redujera la cuota de profesores contratados a tiempo completo del 25 al 10 por ciento; y que se eliminara el requisito de tener cierto número de profesores con posgrado, así como todos aquellos artículos referentes al personal y los salarios dado que según las leyes del trabajo aspectos como estos debían ser tratados en el reglamento intemo de cada institución.

En cuanto al CES, AUPRIDES sugería que esta instancia no tuviera un poder absoluto para controlar al sector, puesto que la responsabilidad última de supervisar la educación superior le competía al gobierno. AUPRIDES exigía, además, que la universidad privada más antigua (UCA) no ocupara un puesto permanente en el CES, y que éste estuviera integrado por tres representantes de las universidades privadas y no dos tal y como se había propuesto.

Pero COSUPES y AUPRIDES no fueron los únicos en hacer sugerencias durante el proceso de legitimización de la ley. Otros actores, entre ellos instituciones educativas y organizaciones privadas, se sumaron al debate público sobre la ley (ver Figura 1). El problema, sin embargo, era que tal debate implicaba tanto más conflicto como actores involucrados en las discusiones. Nuevamente la tensión generada entre los intereses públicos y privados provocó un segundo impasse en el proceso de creación y adopción de la ley de educación superior.

\section{Figura 1}

Participación de los actores más infuyentes en el proceso de creación y adopción de la Ley de Educación Superior

\begin{tabular}{|c|c|c|c|}
\hline $1970-1985$ & $1986-1993$ & $1994-1995$ & $19 \%$ \\
\hline $\begin{array}{l}\text { Identificación } \\
\text { del problema }\end{array}$ & $\begin{array}{l}\text { Formulación de la } \\
\text { política (ley) }\end{array}$ & Legitimización & Implementación \\
\hline MINED & MINED & $\begin{array}{l}\text { Asamblea } \\
\text { Legislativa }\end{array}$ & MINED \\
\hline \multirow[t]{4}{*}{ Otros } & UCA & $\begin{array}{l}\text { MINED } \\
\text { AUPRIDES }\end{array}$ & DES \\
\hline & UES & COSUPES & CES \\
\hline & & UES & $\begin{array}{l}\text { Instituciones de } \\
\text { Educación } \\
\text { Superior }\end{array}$ \\
\hline & & $\begin{array}{l}\text { UCA } \\
\text { Universidades } \\
\text { privadas (no } \\
\text { agrupadas) } \\
\text { Institutos } \\
\text { tecnicos } \\
\text { Organizaciones } \\
\text { de empresarios } \\
\text { Organizaciones } \\
\text { de profesionales } \\
\text { Consejo de } \\
\text { rectores } \\
\text { Agunas } \\
\text { fundaciones } \\
\text { Otros }\end{array}$ & \\
\hline
\end{tabular}

Para salir de este nuevo atolladero, la Comisión de Educación y Cultura decidió realizar un amplio proceso de consulta. Dicho proceso fue apoyado por el MINED, el cual oportunamente había declarado la ejecución de una reforma educativa nacional basada en los principios de participación y consenso ${ }^{21}$. Las primeras consultas se llevaron a cabo entre febrero y marzo de 1995 y consistieron en una serie de reuniones informales y visitas a las diferentes instituciones a fin de lograr una visión más elaborada de lo que en realidad era la oferta educativa disponible. En adición

21. MINED. Memoria de Labores: junio-mayo 1995, Nueva San Salvador, El Salvador, 1995. 
a estos esfuerzos, la Comisión de Educación organizó una conferencia en marzo del mismo año con el propósito de crear las condiciones para alcanzar al menos el consenso sobre la necesidad de adoptar cuanto antes un nuevo marco jurídico para la educación superior. Este objetivo se logro, sin duda alguna, pero el callejón sin salida se formaba al comenzar a tratar el contenido de la ley, particularmente en relación con los requerimientos de calidad, el derecho a la autonomía y el establecimiento del CES.

El tema más polémico, en el fondo, estaba relacionado con la autonomía política y financiera de las instituciones privadas. ¿Por qué? En primer lugar, había temor de que al exigir ciertos requisitos mínimos de calidad se provocara un alza en los costos de operación tal que muchas instituciones privadas no tuvieran más remedio que cerrar o adquirir deudas millonarias a fin de acatar la ley. En segundo lugar, existían dudas en cuanto a hasta qué punto la ley propuesta por el MINED minaba el derecho de autonomía económica ${ }^{22}$. Finalmente, había cierto celo en torno al grado de poder, estructura y funciones que debería tener el CES como entidad controladora del sistema a fin de evitar posibles intervencionismos.

Como resultado de este impasse, tres contra- propuestas fueron presentadas a la Asamblea Legislativa en abril de 1995. Las primeras dos eran de COSUPES y AUPRIDES. En ellas se demandaba el establecimiento de un marco legal menos regulador y la creación de un comité para evaluar la calidad de la educación superior; se proponía al MINED como máximo organismo controlador, y se pedía la incorporación al CES de un representante de las Asociaciones Profesionales (CAPES) y otro del Consejo Nacional de Ciencia y Tecnología (CONACYT).

A fin de desentrampar las negociaciones, la tercera contrapropuesta fue elaborada por el MINED. A diferencia de la anterior, el MINED planté una ley con sólo 95 artículos y con muchos cambios en torno a los temas más controvertidos (ver Cuadro 4). La ley fue menos reguladora, no se especificaban los requerimientos de calidad, exigía sólo un 10 ó 12 por ciento de profesores contratados a tiempo completo, y establecía dos organismos de control con diferentes funciones (DES y CES). Por ser menos rigurosa, la nueva propuesta del MINED fue menos dura para la mayoría de las instituciones privadas. La Universidad de El Salvador, en cambio, la rechazó argumentando que en la nueva propuesta se habían eliminado los artículos que garantizaban el derecho a su suprema autonomía.

\section{Cuadro 4}

La propuesta del MINED (abril 1995): enmiendas relacionadas con los principales puntos de contención

\begin{tabular}{|c|c|}
\hline Puntos de contención & Enmiendas \\
\hline $\begin{array}{l}\text { Requisitos mínimos } \\
\text { de calidad }\end{array}$ & $\begin{array}{l}\text { - Los requisitos mínimos de calidad son generales. Estos deben ser } \\
\text { especificados en otras regulaciones. }\end{array}$ \\
\hline Derechos de autonomía & $\begin{array}{l}\text { - Se dice que todas las instituciones sean estas públicas o privadas } \\
\text { tienen derecho a la autonomía. } \\
\text { - Se exige solamente una cuota de entre } 10 \text { y } 12 \text { por ciento de } \\
\text { profesionales contratados a tiempo completo. Esto se incluye en la } \\
\text { sección referente al personal y no en la de los requisitos mínimos } \\
\text { como se establecía anteriomente. } \\
\text { - Los artículos que otorgaban plena autonomía a la UES son eliminados. }\end{array}$ \\
\hline Organismos de control & $\begin{array}{l}\text { - MINED a través de DES. - CES. Estructura: UES -1, universidades } \\
\text { privadas }-3 \text {, instituciones técnicas }-1 \text {, otras instituciones de educación } \\
\text { superior }-1 \text {, MIPLAN }-1 \text {, organizaciones de empresarios }-1 \text {, } \\
\text { organizaciones de profesionales }-1 \text {. }\end{array}$ \\
\hline
\end{tabular}

22. Esto era planteado por COSUPES, AUPRIDES y otras organizaciones tales como la Cámara de Comercio e Industria de El Salvador, la Asociación Nacional de la Empresa Privada (ANEP), La Fundación para el Desarrollo Económico y Social (FUSADES) y la Fundación Empresarial para el Desarrollo Educativo (FEPADE). 
Hubo necesidad de iniciar un nuevo proceso de consulta. Esta vez se realizaron tres grandes conferencias $^{23}$ y varias reuniones con representantes del sector de educación superior. Pero los debates y actividades de cabildeo continuaron hasta el mes de octubre. Mientras la Universidad de El Salvador demandaba la restitución de sus derechos de autonomía dentro del marco de ley propuesto, AUPRIDES y COSUPES insistían en que la ley era aun muy reguladora y no respetaba el derecho a la autonomía económica. Apoyando esta última postura surge, además, una nueva coalición integrada por los rectores de las universidades privadas conocida como el Consejo de Rectores.

Dada la magnitud de la controversia, el mayor reto que tenían los miembros de la Comisión de
Educación era definir la más razonable y socialmente aceptable ley de educación superior. $\mathrm{Al}$ final, la Comisión determinó pasar al pleno de la Asamblea Legislativa una ley con 68 artículos en donde se incluían cambios fundamentales en relación con los principales puntos de controversia. A diferencia de lo establecido en la última propuesta del MINED, la comisión reconocía en su anteproyecto de ley final el establecimiento de los requisitos mínimos para asegurar la calidad educativa, el reconocimiento en parte de la autonomía de la Universidad de El Salvador, la creación del CES con una estructura distinta y la creación de una Comisión de Acreditación (ver Cuadro 5). Esta fue la propuesta de ley que finalmente fue aprobada por el pleno de la Asamblea Legislativa el 30 de noviembre de 1995.

\section{Cuadro 5}

Propuesta de la Comisión de Cultura y Educación: enmiendas relacionadas con los principales puntos de contencion

\begin{tabular}{|c|c|}
\hline Puntos de contención & Enmiendas* \\
\hline $\begin{array}{l}\text { Requisitos } \\
\text { mínimos } \\
\text { de calidad }\end{array}$ & $\begin{array}{l}\text { - Un mínimo de } 5 \text { carreras profesionales y una carrera técnica. } \\
\text { - Programas de estudio adecuados. } \\
\text { - Infraestructura adecuada. } \\
\text { - Realización de al menos un proyecto de investigación anual. } \\
\text { - Al menos } 1 \text { profesor por cada } 35 \text { alumnos. } \\
\text { - Al menos } 1 \text { profesor contratado a tiempo completo por cada } 65 \text {. } \\
\text { - Los profesores a tiempo completo están obligados a hacer investigación y dar } \\
\text { asesoría a los estudiantes. }\end{array}$ \\
\hline $\begin{array}{l}\text { Derechos } \\
\text { de autonomía }\end{array}$ & $\begin{array}{l}\text { - Se reconoce la autonomía de la UES. } \\
\text { - Se modifican los artículos concemientes al personal. No se habla más de } \\
\text { salarios. }\end{array}$ \\
\hline $\begin{array}{l}\text { Organismos } \\
\text { de control }\end{array}$ & $\begin{array}{l}\text { - Comisión de acreditación. } \\
\text { - MINED a través de la DES. } \\
\text { - CES. Estructura: MINED -2, UES }-1 \text {, universidades privadas }-3 \text {, institutos } \\
\text { técnicos }-1 \text {, asociaciones de empresarios }-1 \text {, organizaciones de profesionales }-1 \text {. }\end{array}$ \\
\hline
\end{tabular}

* Basadas en la Ley de Educación Superior adoptada el 30 de noviembre de 1995.

En general, la ley que se adoptó no fue producto de un consenso absoluto por parte de todos los actores involucrados de alguna manera en el proceso de su formulación y legitimización. En opinión de aquellas instituciones universitarias que se verían más afectadas con la implementación de esta ley, el gobiemo estaría demandando mucho sin ofrecerles ningún tipo de financiamiento o subsidio. Otras afirmaban que quizá el problema real era que sus niveles de ganancia se verían

23. En mayo, agosto y septiembre de 1995. 
obligadamente disminuidos al tener que destinar mayores recursos para mejorar la calidad de sus servicios.

$\mathrm{Si}$ bien es cierto que el nuevo marco jurídico de la educación superior no surgió a partir de un consenso absoluto, lo interesante de éste es que aparece luego de una serie de debates a través de los cuales la tensión entre los intereses públicos y privados es de alguna manera resuelta. De allí que, el potencial de la ley para convertirse en un mecanismo exitoso que garantice a mediano-largo plazo una notable mejoría en la calidad de la educación superior, en alguna medida, radica en esto.

\section{El potencial de una Ley de Educación Superior basada en el consenso}

El potencial de éxito de cualquier política pública en una sociedad democrática depende en parte del nivel de aceptación social que ésta tenga. No obstante, como decíamos al principio, dado que una política pública puede contradecir algunos intereses privados, su grado de aceptación estará supeditado a que tan constructivamente sea resuelta la tensión: público versus privado.

Pueden haber múltiples estrategias para darle solución a tal tensión, pero todas ellas estarán determinadas por el grado de democratización de la sociedad, la existencia de información pertinente y accesible; y la apertura de canales de comunicación entre los hacedores de las políticas y aquellos que se verán directa $\mathrm{o}$ indirectamente afectados por ellas.

En el caso de la creación y adopción de la Ley de Educación Superior, el binomio público versus privado se solucionó gracias a la ejecución de una serie de procesos formales de consulta impulsados por el MINED y la Comisión de Cultura y Educación. El primero de ellos fue iniciativa del ministerio y tuvo como propósito la elaboración de una primera propuesta conjunta de ley la cual integró los acuerdos alcanzados entre la UCA, la UES y el MINED. Este fue un proceso de consulta si bien es cierto de carácter formal, aun muy limitado.

El segundo, por el contrario, se realizó a una escala nacional. Fue un proceso de consulta amplio que requirió la organización de conferencias y reuniones privadas con institutos técnicos,

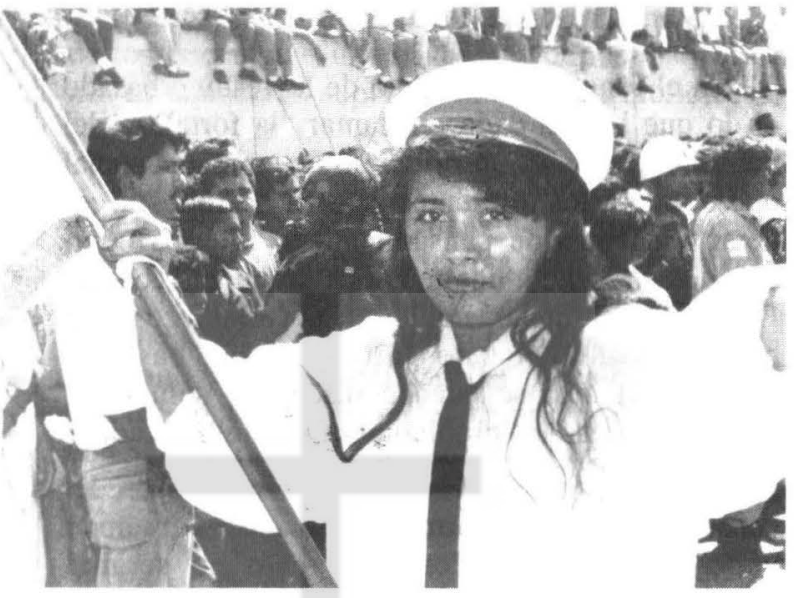

universidades y organizaciones de empresarios, entre otros. Esta iniciativa se dio gracias a la actuación oportuna de la Comisión de Cultura y Educación. Esta vez los esfuerzos estuvieron encaminados a reducir la controversia y posibilitar la apertura de espacios para la discusión y participación de los diferentes actores en el proceso de formulación de la ley.

Lo que tuvieron en común estos dos procesos de consulta (el limitado y el ampliado) fue que ambos se utilizaron en los momentos más críticos del proceso de creación y adopción de la Ley de Educación Superior. En consecuencia, podríamos afirmar que "la consulta", en tanto que estrategia, fue usada para desentrampar al proceso y dar paso a la adopción y posterior implementación del nuevo marco jurídico de la educación superior.

En tanto que método, se pudo implementar debido a los siguientes factores: (a) la existencia de una entidad facilitadora capaz de coordinar responsablemente las discusiones. Nos referimos a la participación del MINED y la Comisión de Cultura y Educación. (b) La necesidad de obtener información a fin de tomar decisiones más razonables y realistas. (c) El grado de credibilidad de los actores en el proceso. (d) La habilidad negociadora de los que formularon la ley. (e) La determinación del MINED de completar la reforma al marco legal de la educación salvadoreña en el contexto de la reforma nacional.

Y, en tanto que proceso, "la consulta" no sólo facilitó la negociación entre diferentes actores sociales a fin de resolver un problema de carácter nacional, sino que también contribuyó a crear las 
condiciones para determinar una política educativa "socialmente aceptable".

En el fondo, este proceso de ley estuvo basado en lo que hemos dado en llamar "la fortaleza del consenso". Este es un principio de conducta social que obliga a los diferentes actores o grupos a generar esquemas de pensamiento y criterios compartidos en tomo a una temática de interés común. Para ello es fundamental que se establezca una metodología de trabajo participativa y básica a partir de la cual se pueden discutir y solucionar razonablemente los problemas del conglomerado.

En este sentido, el valor más importante del consenso estaría mayormente asociado al método y no al resultado. Pero que esto no se mal entienda, puesto que los resultados también son importantes. Lo que pretendemos explicar es que, en la práctica, cuando hay serios conflictos de intereses en la definición de una política pública como en el caso de este proceso de ley, siempre hay que saber escoger. Es decir, que los hacedores de la política pública deben ser muy cuidadosos a la hora de decidir qué combinación de intereses podría ser la más adecuada o bien la más socialmente aceptable.

Sin duda, la creación y adopción de cualquier política pública es un proceso altamente político. $Y$ es por eso que establecer una metodología de consenso puede ser muy útil. No sólo contribuiría a reducir posibles tensiones sino también a crear las mejores condiciones para establecer el "mínimo compromiso social" e implementar sin ningún apuro cualquier política pública.

De allí que, de conformidad con el proceso que se siguió para su creación y adopción, la Ley de Educación Superior se ha convertido a nivel social en el referente principal que todas las universidades e institutos técnicos deben seguir a la hora de cumplir con el compromiso de mejorar la calidad de la educación que actualmente ofrecen.

Algunos avances ya se han dado en la etapa de implementación de la ley. Se otorgó a las instituciones de educación superior un período de gracia de dos años (1996-1997) para que pudieran cumplir los requisitos mínimos de calidad. Se creó el CES. Luego, en 1997, se estableció el Sistema de Mejoramiento de la Calidad de las Instituciones de Educación Superior el cual tendrá a su cargo la coordinación de un subsistema de calificación, uno de evaluación y otro de acreditación. De hecho, ya se ha comenzado con el proceso de evaluación de las instituciones en lo que respecta a sus recursos humanos y financieros, infraestructura, costos y otras características que ayudarán a determinar la calidad de sus servicios educativos.

La evaluación se está llevando a cabo en dos etapas. En la primera, cada institución es responsable de autoevaluarse siguiendo los criterios de calidad impuestos por el Ministerio de Educación. Según se ha afirmado, los resultados de la etapa de autoevaluación deberán ser publicados a finales de octubre del presente año. Mientras que en la segunda, el MINED deberá verificar si los resultados de la autoevaluación son coherentes con la realidad. De allí que se espera que a finales de febrero de 1998 se conozca públicamente la primera evaluación de las instituciones de educación superior. También, en lo que va del año, ya fueron cerradas varias carreras de estudio y una universidad, la Universidad de Administración de Negocios. Y se está cuestionando el cierre de entre 10 y 15

universidades más.

Pero, ¿puede una metodología de consenso garantizar que esta ley constituya un mecanismo auténtico que ayude a resolver los problemas actuales de la educación superior?... Sólo en parte. Hay otros factores claves que son relevantes a la hora de implementar la ley:

(A) La función de los organismos de control. Por un lado, es indispensable que el Consejo de Educación Superior funcione con autoridad y adquiera mayor presencia pública. Y, por otro lado, es imprescindible que el MINED desempeñe siempre una función activa y oportuna en la fase de implementación de la nueva ley. Parte de sus esfuerzos deberían estar concentrados en la redefinición de las funciones de la Dirección de Educación Superior (DES). Para garantizar la continuidad en la implementación de la ley, la DES debe asegurar y hacer efectiva su capacidad de gestión no sólo supervisando la puesta en marcha de la ley, sino también creando los canales 
de comunicación que le permitan identificar las necesidades y problemas que puedan existir en todas las instituciones al acatar las nuevas regulaciones.

Considerando lo difícil y controvertido que fue el proceso de creación y adopción de la Ley de Educación Superior, debe tomarse en cuenta que pese a que ha habido un acuerdo mínimo que hace que la puesta en marcha de la ley sea algo ineludible, aun existe cierta resistencia por parte de algunas instituciones, quizá de aquellas que se ven más afectadas por la ley, a demorar su implementación. Para el caso, ya se han presentado algunas irregularidades en la autoevaluación de las universidades. De hecho, se presume que algunas instituciones pequeñas pudieron haber declarado poseer la misma cuantía de servicios y recursos que aquellas universidades más grandes y con mayor antigüedad.

Para evitar la flexibilidad y el descontrol en la aplicación de las nuevas regulaciones, los organismos de control deberían continuar imponiendo medidas estrictas de vigilancia y supervisión. $Y$ en caso de presentarse otras anomalías, estos deberían imponer sanciones públicas sin ningún titubeo.

(B) Disponibilidad de recursos financieros. No todas las universidades están en capacidad de cumplir los requisitos mínimos de calidad a menos que tengan los recursos financieros para hacerlo. De aproximadamente 41 universidades actualmente abiertas, sólo unas pocas estarán próximas a la excelencia en términos de calidad. Una buena parte, quizá todas aquellas que no están preparadas para ajustarse rápidamente a las nuevas exigencias, no tendrán más remedio que desaparecer. Y un número significativo y con posibilidad de adquirir créditos bancarios millonarios, tendrá la posibilidad de responder a las nuevas exigencias. Ahora bien, a largo plazo, el reto para éstas últimas será saber asegurar su estabilidad financiera de tal forma que puedan siempre invertir en mejorar la calidad de sus servicios.

Para contribuir en la conversión y desarrollo cualitativo del sector de educación superior, el gobiemo podría ofrecer una serie de incentivos financieros. Por ejemplo, sería bueno que se crearan fondos de financiamiento para impulsar la investigación y la difusión de sus resultados; facilitar a las universidades e institutos técnicos la venta de sus servicios de investigación o asesoría a las empresas; financiar los estudios de posgrado de los docentes e investigadores de las instituciones de educación superior; mejorar las bibliotecas, etc.

(C) Diseño de planes estratégicos. Las universidades, institutos técnicos y los organismos de control deben comprometerse a planificar sus propias estrategias de acción encaminadas a mejorar la calidad de la educación superior. Esto ayudaría a garantizar la continuidad del proceso de implementación de la ley en el tiempo, y la toma de conciencia institucional sobre la importancia de operar siguiendo los criterios de excelencia para formar profesionales o técnicos competentes.

En suma, el potencial de la Ley de Educación Superior en la sociedad salvadoreña depende de varios factores. El grado de aceptación social que esta ley tenga per se es indispensable pero no el único factor que mejore de manera significativa la calidad de la educación superior. La función de los organismos de control, los recursos financieros disponibles y la planificación estratégica son ť́umbién fundamentales.

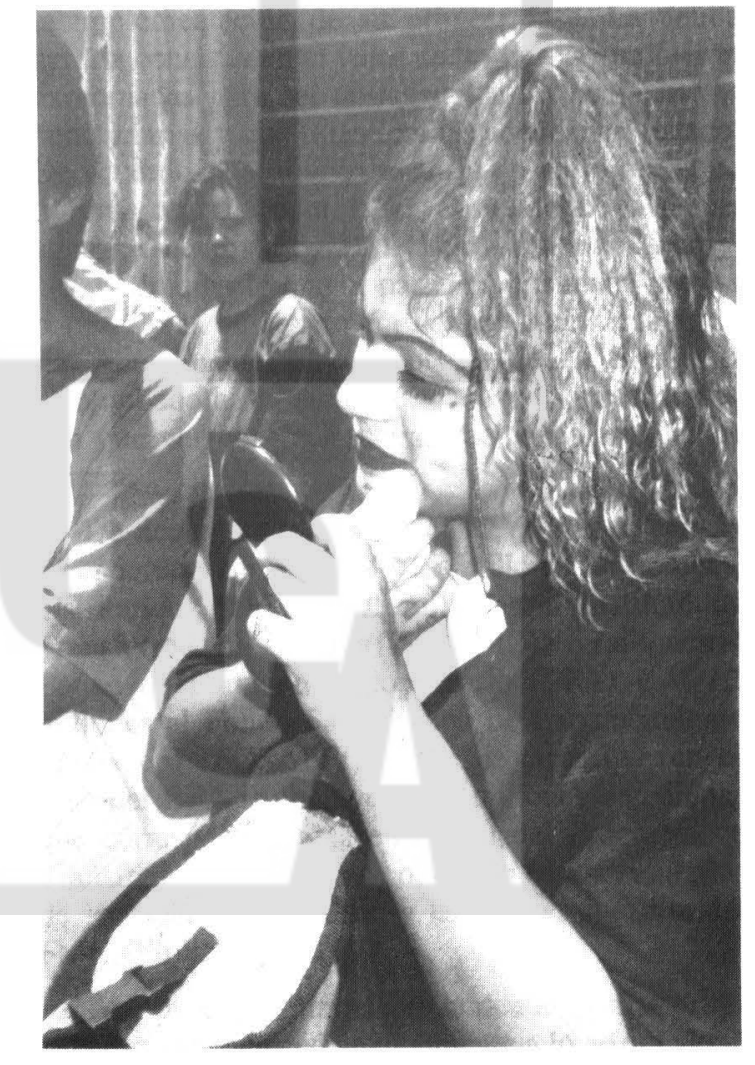




\section{La política pública en una sociedad demo- crática}

Cabe mencionar que el proceso de creación y adopción de la Ley de Educación Superior, aun con toda la controversia que generó, nos deja varias lecciones interesantes.

Al parecer, éste es uno de los pocos casos, sino el primero, en donde la formulación y legitimización de una política educativa pública se realiza usando una metodología de consenso. Aparentemente, el haber pasado por esta experiencia abrió los ojos de los gestores de la ley para tomar en cuenta maneras distintas de hacer políticas gubernamentales.

No es mera coincidencia el que una vez que la Ley de Educación Superior fuera adoptada, otros procesos de ley hayan seguido la misma metodología de consenso. Por ejemplo, en el campo de la educación tenemos el estudio de la Ley de la Carrera Docente y la Ley General de Educación.

Sin duda alguna, el proceso de creación y adopción de la Ley de Educación Superior nos enseña que es posible hacer políticas públicas basadas en la participación y el consenso. Esta es una gran lección para las instancias encargadas de la cuestión pública las cuales pareciera que, en la nueva coyuntura, han perdido su habilidad para justificar su tendencia a ignorar las demandas individuales en relación con los grandes problemas sociales. Estas necesitan ahora cambiar las maneras de hacer las políticas públicas y dar lugar a formas menos autoritarias y más participativas de gestión.

Pero no sólo se requiere buena voluntad, profesionalismo y responsabilidad social para poner esto en práctica, sino también se necesitan crear los mecanismos adecuados, mejorar los canales de comunicación institucionales, facilitar el acceso a información, y contar con equipos asesores capaces de identificar problemas y dar soluciones que sean aceptables socialmente. Al final, con esto se estaría contribuyendo a democratizar las estructuras, especialmente aquellas desde donde se deciden los destinos de la nación. 